\title{
Continuum damage description for a discrete crack modeling approach for delamination migration in composite laminates
}

\author{
D.C. Pham, X. Cui, J. Lua \\ Global Engineering and Materials, Inc. \\ 1 Airport Place, Princeton, NJ 08540 \\ D. Zhang \\ Department of Mechanical Engineering, University of Connecticut \\ 191 Auditorium Road, Unit 3139, Storrs, CT 06269-3139
}

\begin{abstract}
A three-dimensional discrete crack embedded within a continuum damage mechanics (CDM) model is developed for an effective characterization of delamination migration in composite laminates subjected to static loading. 3D Hashin failure criterion is implemented for damage initiation prediction under a 3D stress state. Matrix crack initiation criteria coupled with a maximum principal stress direction are employed to determine the location and orientation of a discrete matrix crack within an element. Given the orientation of the initiated matrix crack, the resulting stiffness degradation is characterized in the local principal stress coordinate system and an energy driven failure mechanism is included to capture the crack growth. By coupling the cohesive model for delamination and the discrete damage embedded CDM for matrix cracking, their synergistic interaction can be captured during the simulation of the delamination migration. The predictive capability of the enhanced modeling strategy is examined through simulation of a delamination migration in a cross-ply tap laminate. The predicted results are compared with the experimental data published by NASA and good agreements are achieved in terms of load displacement curve and the location of crack branching.
\end{abstract}

\begin{aligned}$C D M & \multicolumn{1}{c}{$ Nomenclature } \\ $F N M & =$ fontinuum damage mechanics \\ $S E R R & =$ strain energy release rate \\ $\left\{\sigma_{i j}\right\},\left\{\varepsilon_{i j}\right\} & =$ stresses, strains in the local material coordinate \\ $\left\{\sigma_{i j}^{\prime}\right\},\left\{\varepsilon_{i j}^{\prime}\right\} & =$ stresses, strains in the principal stress coordinate \\ ${[S],\left[S^{\prime}\right] } & =$ compliance matrices in the local material and the principal stress coordinates \\ $F I_{F T} & =$ failure index for fiber tension mode \\ $F I_{F C} & =$ failure index for fiber compression mode \\ $F I_{M T} &$ failure index for matrix tension mode \\ $F I_{M C} & =$ failure index for matrix compression mode \\ $d_{F T} & =$ fiber tension damage variable \\ $d_{F C} & =$ fiber compression damage variable \\ $d_{M T} & =$ transverse tension damage variable \\ $d_{M C} & =$ transverse compression damage variable \end{aligned}




\section{Introduction}

$\mathrm{F}$ AILURE mechanisms in laminated composites are complicated due to the presence of matrix cracking, delamination, fiber fracture and kink banding. Delamination migration has been observed in composite tapelaminates where a delamination crack can jump from one interface to another via the intra-ply matrix cracking. This problem has been selected as a benchmark problem to examine the modeling capability in capturing the interaction of matrix cracking and delamination. The presence of the stress concentration ahead of a delamination crack will activate a matrix crack along its favorable low energy path. The propagating delamination crack will intersect with another ply interface and the resulting intensified stress field will initiate a new delamination crack followed by its growth. To fully capture this failure process, discrete matrix crack has to be included in the modeling process.

Given the limitation of a conventional continuum damage mechanics (CDM) model in capturing the stiffness degradation resulting from a discrete matrix crack, various modeling techniques have been developed to explicitly describe the kinematics of a discrete matrix crack, such as the phantom paired extended finite element method, ${ }^{1-2}$ the regularized extended finite element method, ${ }^{3-5}$ the augmented finite element method, ${ }^{6}$ and the floating node method. ${ }^{7}$ To characterize the energy driven crack propagation process, a cohesive interface is injected at a newly inserted crack surface that does not require conforming to an existing finite element mesh. Additional computational cost will be added in the description of a discontinuous displacement field associated with each crack within a meshindependent framework. For a large-scale 3D geometry, the resulting computational cost can be quite expensive for co-simulation of delamination and matrix crack growth.

The effect of a discrete crack has not been incorporated explicitly in a conventional CDM model due to its inability to handle the crack orientation dependent stiffness degradation. The intra-ply damage in the CDM model is described based on the failure mechanisms associated with fiber or matrix under tension or compression. When a matrix failure mode is detected, all the matrix dominant properties are degraded without considering the orientation of the matrix cracking. A refined model on matrix cracking has been frequently used by assuming that the crack surface is normal to the ply interface and its direction is in parallel with the fiber direction. This constrained matrix crack surface is unable to describe the curved or inclined matrix cracking observed in the delamination migration problem. Without capturing the path of the matrix crack, both the crack branching and the initiation of the second delamination at a distinct interface cannot be simulated using the energy driven fracture process.

A metric migration testing case has been selected by many researchers as a benchmark problem to study the interaction of matrix cracking and delamination. Both experimental and numerical studies of delamination migration problems have been performed recently to explore the interaction of delamination and matrix cracking and the migration location that is a function of specimen geometry and loading position. Ratcliffe et al. ${ }^{8}$ investigated migration of delamination in a carbon/epoxy tape laminates where the delamination was triggered by a Teflon insert between the 0 and 90 plies. Fractography of the specimens showed the delamination development and kinking from the first [0/90] interfaces to adjacent 90 interfaces through both stable and unstable events. De Carvalho et al. ${ }^{7}$ integrated the floating node method (FNM) with the virtual crack closure technique to predict the delamination propagating and migrating for the tape laminates. Matrix cracking and delamination were modeled within the same FNM elements and the method well captured the experimental data and observation. Pernice et al. ${ }^{9}$ extended the delamination migration tests to angle-ply laminates with ply orientations $\theta=60^{\circ}$ and $75^{\circ}$. Two main stages for migration were recorded: delamination first initiates from $[0 / \theta]$ interface, transforming to intra-ply cracks through $\theta$ ply bunches, and continue to grow as delamination in the $[\theta / 0]$ interface. Much attention and research efforts, as can be seen, are given to the use of XFEM-based methods to model discrete cracks such as the FNM whereas interply delamination is handled by cohesive element method. ${ }^{1-7} \mathrm{~A}$ multiscale approach with a discrete damage modeling has been developed by Mollenhauer et al. ${ }^{5}$ by embedding a local model within a global model at ply level. A cohesive interface has been introduced at the interface between each individual fiber and its surrounding matrix in a micro-scale model. In addition, discrete matrix cracks in the resin-rich zones are simulated in the micro-scale model using the regularized X-FEM.

Discrete modeling approach has shown its ability in capturing the failure sequence of a delamination migration problem. For its implementation within a commercial finite element solver such as ABAQUS, a user-defined element has to be developed for the kinematic description of a discrete matrix crack. For a large composite structure with an extensive distribution of matrix cracks, the resulting computational effort for tracking each matrix crack will be intensive, and it is sometimes challenging to obtain a convergent solution with a large population of matrix cracks. While a CDM approach can be used to remedy this numerical difficulty and provides an efficient solution, the crack orientation dependent stiffness degradation is not included to account for the effect of the presence of a discrete crack. To retain the computational efficiency without penalizing the fidelity in damage characterization, it is rational to enhance the CDM model with an embedded matrix crack of its arbitrary orientation. 
In this work, we will first summarize the key components of the continuum description of discrete matrix cracking and its interaction with delamination. 3D Hashin failure criterion ${ }^{10}$ with an energy driven damage accumulation is implemented for the intra-ply damage evolution under a general 3D stress state. Different from a conventional CDM approach, a maximum principal stress direction is determined at a potential site for matrix crack initiation. Using a crack band modeling approach, ${ }^{11,12}$ a matrix damage index is computed based on the energy dissipated and the critical value of the energy release rate. Given the potential orientation of the inserted matrix crack, a rational stiffness reduction is applied with respect to the local coordinate system of the cracked element. The compliance matrix is updated due to the crack opening induced material softening. The stiffness matrix in the principal material planes is determined based on the transformation of the compliance matrix from the cracked element coordinate system to its local material coordinate system followed by its matrix inversion. The inter-ply delamination initiation and propagation is characterized using a native Abaqus cohesive element. Both the applicability and validity of the developed modeling approach is demonstrated by comparing the simulation results with testing data reported by Ratcliffe et al. ${ }^{8}$ for the delamination migration in a cross-ply laminates.

\section{Overview of CDM description of a discrete matrix crack}

The 3D Hashin failure criterion ${ }^{10}$ is employed to determine the constituent failure induced composite damage initiation. The 3D Hashin criterion distinguishes matrix and fiber failure modes under tension and compression loading cases by the following equations:

- Tensile fiber failure (FT) for $\sigma_{11} \geq 0$ :

$$
F I_{F T}=\left(\frac{\sigma_{11}}{X_{T}}\right)^{2}+\frac{\sigma_{12}^{2}+\sigma_{13}^{2}}{S_{12}^{2}}= \begin{cases}\geq 1 & \text { failure } \\ <1 & \text { no failure }\end{cases}
$$

- Compressive fiber failure (FC) for $\sigma_{11}<0$ :

$$
F I_{F C}=\left(\frac{\sigma_{11}}{X_{C}}\right)^{2}= \begin{cases}\geq 1 & \text { failure } \\ <1 & \text { no failure }\end{cases}
$$

- Tensile matrix failure (MT) for $\sigma_{22}+\sigma_{33}>0$ :

$$
F I_{M T}=\frac{\left(\sigma_{22}+\sigma_{33}\right)^{2}}{Y_{T}^{2}}+\frac{\sigma_{23}^{2}-\sigma_{22} \sigma_{33}}{S_{23}^{2}}+\frac{\sigma_{12}^{2}+\sigma_{13}^{2}}{S_{12}^{2}}= \begin{cases}\geq 1 & \text { failure } \\ <1 & \text { no failure }\end{cases}
$$

- Compressive matrix failure (MC) for $\sigma_{22}+\sigma_{33}<0$ :

$$
F I_{M C}=\left[\left(\frac{Y_{C}}{2 S_{23}}\right)^{2}-1\right]\left(\frac{\sigma_{22}+\sigma_{33}}{Y_{C}}\right)+\frac{\left(\sigma_{22}+\sigma_{33}\right)^{2}}{4 S_{23}^{2}}+\frac{\sigma_{23}^{2}-\sigma_{22} \sigma_{33}}{S_{23}^{2}}+\frac{\sigma_{12}^{2}+\sigma_{13}^{2}}{S_{12}^{2}}= \begin{cases}\geq 1 & \text { failure } \\ <1 & \text { no failure }\end{cases}
$$

where $X_{T}, X_{C}, Y_{T}, Y_{C}, S_{12}, S_{13}, S_{23}$ are longitudinal tensile strength, longitudinal compressive strength, transverse tensile strength, transverse compressive strength, in-plane shear strength and out-of-plane shear strength, respectively. Post-peak failure in each failure mode is modeled by a crack band approach. In the crack band approach, it is assumed that distributed cracks are "smeared" out over a certain width within a finite element such that the effect of progressive cracking is represented by macroscopic strain softening in a continuum scheme. To restore mesh objectivity, a characteristic length is introduced such that the total amount of energy dissipated during failure in a continuum element is equal to the fracture toughness (or the critical strain energy release rate, SERR) defined for a cohesive element of the same size. ${ }^{14,15}$ For composites, the crack band approach assumes that the crack evolution under each failure mode is governed by SERR in the respective mode. ${ }^{12-15}$ Different from the existing approach based on a 2D stress state, a full 3D stress state is considered to determine the failure initiation. For an element of its characteristic length of $L^{c}$, the energy dissipation due to each failure mode is dictated by $G_{i}$ as:

$$
\int \sigma_{e q}^{i} d\left(\varepsilon_{e q}^{i} L^{c}\right)=G_{i} \quad(i=F T, F C, M T, M C)
$$


where $\delta_{f}^{i}, \sigma_{e q}^{i}, \varepsilon_{e q}^{i}$ and $\delta_{e q}^{i}$ are the total crack length and equivalent stress, strain and crack displacement of each failure mode. The equivalent displacements and stresses that account for the combined effects of 3D stresses become:

- $\quad$ Fiber tension and compression:

$$
\begin{aligned}
& \delta_{e q}^{f t}=L^{c} \sqrt{\left\langle\varepsilon_{11}\right\rangle^{2}+\alpha \varepsilon_{12}^{2}+\alpha \varepsilon_{13}^{2}} \\
& \sigma_{e q}^{f t}=\frac{\left\langle\sigma_{11}\right\rangle\left\langle\varepsilon_{11}\right\rangle+\alpha \tau_{12} \varepsilon_{12}+\alpha \tau_{13} \varepsilon_{13}}{\delta_{e q}^{f t} / L^{c}} \\
& \delta_{e q}^{f c}=L^{c}\left\langle-\varepsilon_{11}\right\rangle \\
& \sigma_{e q}^{f c}=\frac{\left\langle-\sigma_{11}\right\rangle\left\langle-\varepsilon_{11}\right\rangle}{\delta_{e q}^{f c} / L^{c}}
\end{aligned}
$$

- Matrix tension and compression

$$
\begin{aligned}
& \delta_{e q}^{m t}=L \sqrt{\left\langle\varepsilon_{22}\right\rangle^{2}+\left\langle\varepsilon_{33}\right\rangle^{2}+\varepsilon_{23}^{2}+\varepsilon_{12}^{2}+\varepsilon_{13}^{2}} \\
& \sigma_{e q}^{m t}=\frac{\left\langle\sigma_{22}\right\rangle\left\langle\varepsilon_{22}\right\rangle+\left\langle\sigma_{33}\right\rangle\left\langle\varepsilon_{33}\right\rangle+\tau_{23} \varepsilon_{23}+\tau_{12} \varepsilon_{12}+\tau_{13} \varepsilon_{13}}{\delta_{e q}^{m t} / L^{c}} \\
& \delta_{e q}^{m c}=L \sqrt{\left\langle-\varepsilon_{22}\right\rangle^{2}+\left\langle-\varepsilon_{33}\right\rangle^{2}+\varepsilon_{23}^{2}+\varepsilon_{12}^{2}+\varepsilon_{13}^{2}} \\
& \sigma_{e q}^{m c}=\frac{\left\langle-\sigma_{22}\right\rangle\left\langle-\varepsilon_{22}\right\rangle+\left\langle-\sigma_{33}\right\rangle\left\langle-\varepsilon_{33}\right\rangle+\tau_{23} \varepsilon_{23}+\tau_{12} \varepsilon_{12}+\tau_{13} \varepsilon_{13}}{\delta_{e q}^{m c} / L^{c}}
\end{aligned}
$$

where $\langle\sigma\rangle$ are Macaulay operator defined as $\langle\sigma\rangle:=(\sigma+|\sigma|) / 2$. Denoting $\delta_{e q}^{0 i}$ as initial equivalent failure strain at the damage onset and $\delta_{e q}^{F i}$ as the ultimate equivalent failure strains for each failure mode, the internal damage variables $d_{i}(i=f t, f c, m t, m c)$ are defined for each mode based on the linear softening law. The damage variables $d_{i}$ are computed by Eq. 10 taking the initial value of 0 for the initial damage and unit for the complete failure.

$$
d_{i}=\frac{\delta_{e q}^{F i}\left(\delta_{e q}^{i}-\delta_{e q}^{0 i}\right)}{\delta_{e q}\left(\delta_{e q}^{F i}-\delta_{e q}^{0 i}\right)}, \quad \delta_{e q}^{0 i} \leq \delta_{e q}^{i} \leq \delta_{e q}^{F i}, \quad i=f t, f c, m t, m c
$$

Once the damage initiation criterion is satisfied (Eqs. 1-4), the principal crack plane normal to $\alpha$ is introduced and calculated from the current stress state as in Eq. 11. The principal crack coordinate (2'-3') is marginally created by rotating the (2-3) material plane by an angle $\alpha$. Unlike conventional CDM where the material stiffness degradation is carried out in the material plane, the proposed 3D CDM considers stiffness reduction to be performed in the principal stress coordinate system. It should be noted the crack plane normal vector is always aligned with the 2'-axis, and thus the elastic modulus along the 3'-axis is assumed to remain intact when the crack opens.

$$
\alpha=\frac{1}{2} \tan ^{-1}\left(\frac{2 \tau_{23}}{\sigma_{2}-\sigma_{3}}\right)
$$




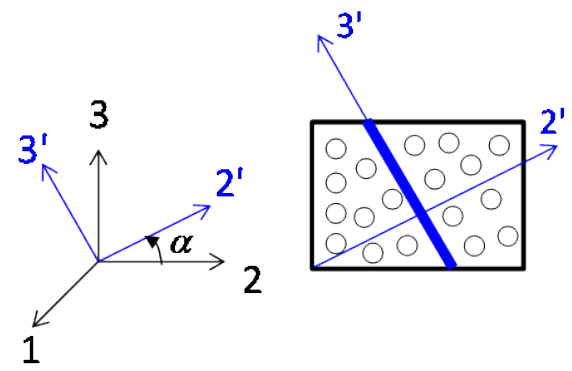

Stiffness degradation scheme for tension and compression failure in the principal crack coordinate are expressed as:

$$
\left\{\begin{array}{l}
E_{1}^{\prime}=\left(1-d_{f t / f c}\right) E_{1} \\
E_{2}^{\prime}=\left(1-d_{m t / m c}\right) E_{2} \\
G_{23}^{\prime}=\left(1-d_{m t / m c}\right) G_{23} \\
E_{3}^{\prime}=E_{3} \\
G_{12}^{\prime}=\left(1-d_{m t / m c}\right) G_{12} \\
G_{13}^{\prime}=\left(1-d_{m t / m c}\right) G_{13}
\end{array}\right.
$$

where $d_{f t}, d_{f c}, d_{m t}, d_{m c}$ are the scalar damage variables computed in Eq. 10. $E_{1}, E_{2}, E_{3}, G_{12}, G_{13}, G_{23}$ are the virgin elastic and shear moduli of the composite material, and $E_{1}^{\prime}, E_{2}^{\prime}, E_{3}^{\prime}, G_{12}^{\prime}, G_{13}^{\prime}, G_{23}^{\prime}$ are the corresponding degraded properties. The compliance stiffness matrix is then formulated with the degraded properties in the principal stress coordinate as:

$$
\left\{\varepsilon^{\prime}\right\}=[\bar{S}]\left\{\sigma^{\prime}\right\}
$$

The compliance matrix is then transformed back to the material coordinate as in Eq. 14 through the transformation matrix [T] given in Eq. 15.

$$
\begin{aligned}
& {[S]=[\mathrm{T}(\alpha)]^{T}[\bar{S}][\mathrm{T}(\alpha)]^{-1}} \\
& T=\left[\begin{array}{cccccc}
1 & 0 & 0 & 0 & 0 & 0 \\
0 & \cos ^{2} \alpha & \sin ^{2} \alpha & 0 & 0 & \cos \alpha \sin \alpha \\
0 & \sin ^{2} \alpha & \cos ^{2} \alpha & 0 & 0 & -\cos \alpha \sin \alpha \\
0 & 0 & 0 & \cos \alpha & -\sin \alpha & 0 \\
0 & 0 & 0 & \sin \alpha & \cos \alpha & 0 \\
0 & -2 \sin \alpha \cos \alpha & 2 \sin \alpha \cos \alpha & 0 & 0 & \cos ^{2} \alpha-\sin ^{2} \alpha
\end{array}\right]
\end{aligned}
$$

When the proposed failure model is implemented as a user-defined material subroutine in a commercial finite element software such as Abaqus, it requires the computation of the material stiffness matrix. In this study, secant stiffness [C] is used to dictate the softening behavior. The element constitutive relation is finally expressed in Eq. 16, where the stiffness [C], which is computed as the inverse of the compliance matrix [S], keeps updating based on the damage progression at each increment.

$$
\{\sigma\}=[C]\{\varepsilon\}=[S]^{-1}\{\varepsilon\}
$$

A summary of the solution process for the CDM based description of a discrete matrix crack is given in Fig. 1. Given a 3D stress state at a Gaussian point of a solid element, 3D Hashin criterion is used to determine the matrix crack initiation. Based on the maximum principal stress, the orientation of a potential matrix crack is located and the 
compliance matrix is updated with respect to the local cracked element coordinate system to reflect the crack opening induced material softening. Based on the crack band model coupled with the energy driven damage state, material properties are degraded in the cracked element coordinate system and used to update the compliance matrix. After the transformation of the updated compliance matrix to its composite material coordinate system, the corresponding stiffness matrix is computed via the matrix inversion.

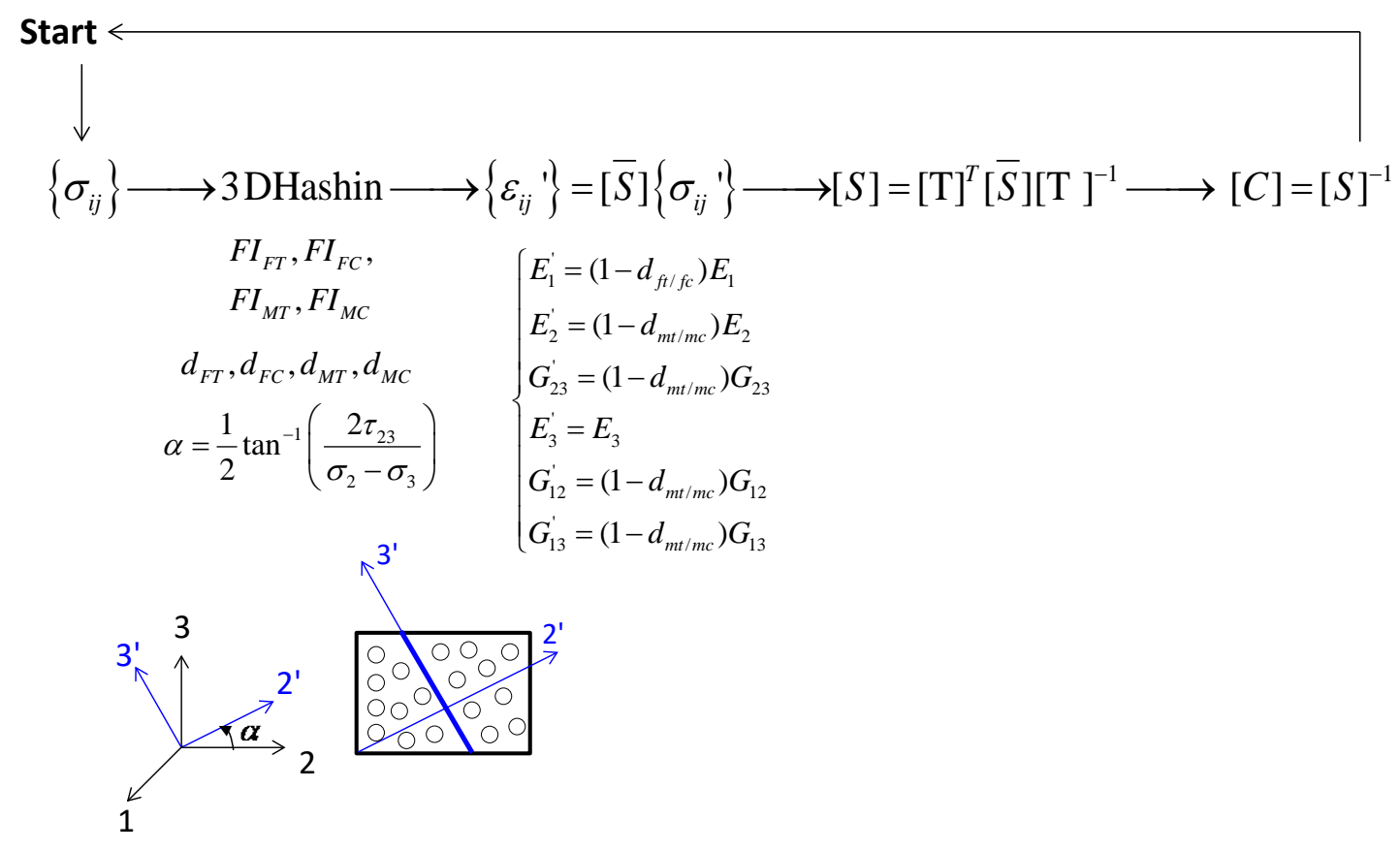

Figure 1. A solution logic diagram for the enhanced CDM based intra-ply damage characterization

Unlike the intra-ply damage prediction described above, inter-ply delamination is characterized using an existing Abaqus' cohesive element based on a mixed mode traction-separation law. Delamination onset is assumed to follow a quadratic failure criterion:

$$
\frac{\left\langle\sigma_{n}\right\rangle^{2}}{N^{2}}+\frac{\sigma_{s}^{2}}{S^{2}}+\frac{\sigma_{t}^{2}}{T^{2}}=1
$$

where $\sigma_{n}, \sigma_{s}, \sigma_{t}$ are the normal and two shear tractions and $N, S, T$ are the corresponding normal and shear interfacial strength. For mixed mode delamination, equivalent traction $T_{e q}$ and displacement $\delta_{e q v}^{\text {int }}$ are introduced, and delamination propagation is indicated by a mixed-mode energy Benzeggagh and Kenane law:

$$
\begin{aligned}
& G_{e q c}=G_{I c}^{\mathrm{int}}+\left(G_{I I c}^{\mathrm{int}}-G_{I c}^{\mathrm{int}}\right)\left(\frac{G_{I I}+G_{I I I}}{G_{I}+G_{I I}+G_{I I I}}\right)^{\eta} \\
& \int T_{e q} d \delta_{e q v}^{\mathrm{int}}=G_{e q c}
\end{aligned}
$$




\section{Application of enhanced damage prediction module for prediction of delamination migration}

Prior to the demonstration of the applicability of the enhanced CDM solution module, a summary of a delamination migration test of a cross-ply laminate is given first. Ratcliffe et al. ${ }^{8}$ performed migration tests of DCB composite specimens under tension loading. The tested specimens are IM7/8552 cross-ply tapes with a gauge length of $115 \mathrm{~mm}$, a width of $12.7 \mathrm{~mm}$ and a total thickness of $5.25 \mathrm{~mm}$. Two sets of the IM7/8552 material properties available in the literature are listed in Tables 1 and 2. The specimen layup is $\left[90_{4} / 0_{3} /(90 / 0)_{2 s} / 0_{3} / 90_{4} / \mathbf{0} / 90_{4} / 0_{2} /(90 / 0)_{2 s} / 0_{2} / 90_{3} / 0 / 90\right]$. Teflon was inserted in the bottom $0 / 90$ interface, as indicated in red, to trigger the delamination along this interface. The pre-cracked length of the specimen by Teflon is $a=49 \mathrm{~mm}$. Vertical tension load is applied on top of the specimen via a loading rod and a piano hinge. Two sides of the specimens are clamped to the aluminum baseplates as shown in Fig. 2.
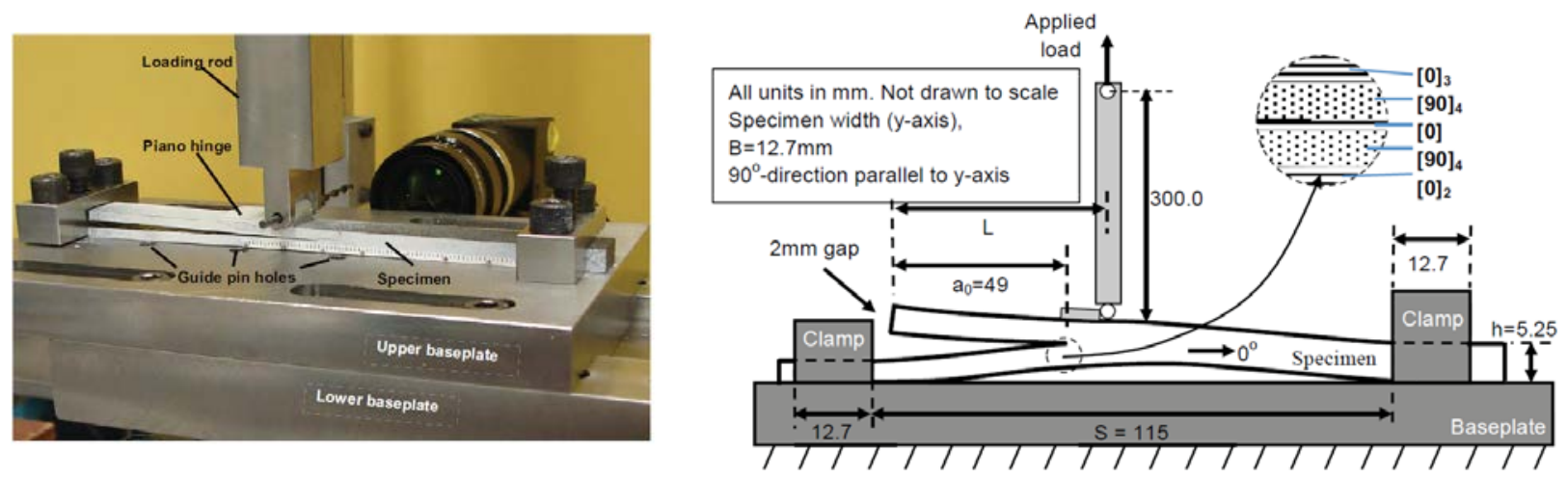

Figure 2. Setup of delamination migration test ${ }^{8}$

Table 1 IM7/8552 materials properties ${ }^{8}$

\begin{tabular}{ccclll}
\multicolumn{5}{c}{1 f fiber direction; 2 = transverse-to-fiber direction; 3 = through-thickness direction } \\
$\boldsymbol{E}_{\mathbf{1 1}}$ & $\boldsymbol{E}_{22}=\boldsymbol{E}_{\mathbf{3 3}}$ & $\boldsymbol{G}_{\mathbf{1 2}}=\boldsymbol{G}_{\mathbf{1 3}}$ & $\boldsymbol{G}_{\mathbf{2 3}}$ & $\boldsymbol{v}_{\mathbf{1 2}}=\boldsymbol{v}_{\mathbf{1 3}}$ & $\boldsymbol{v}_{\mathbf{2 3}}$ \\
$161 \mathrm{GPa}$ & $11.4 \mathrm{GPa}$ & $5.17 \mathrm{GPa}$ & $3.98 \mathrm{GPa}$ & 0.32 & 0.436 \\
$\boldsymbol{Y}_{\boldsymbol{t}}$ & $\boldsymbol{S}_{\mathbf{1 2}}$ & $G_{I c}^{m}=G_{I c}^{\text {int }}$ & $G_{I I c}^{m}=G_{I I}^{\text {int }}$ & & \\
$60 \mathrm{MPa}$ & $90 \mathrm{MPa}$ & $0.21 \mathrm{~kJ} / \mathrm{m}^{216}$ & $0.77 \mathrm{~kJ} / \mathrm{m}^{216}$ & & \\
\hline
\end{tabular}

Table 2 IM7/8552 materials properties ${ }^{17}$

\begin{tabular}{|c|c|c|c|c|c|}
\hline \multicolumn{6}{|c|}{1 = fiber direction; 2 = transverse-to-fiber direction; 3 = through-thickness direction } \\
\hline $\begin{array}{l}\boldsymbol{E}_{11} \\
157.2 \mathrm{GPa}\end{array}$ & $\begin{array}{l}\boldsymbol{E}_{22}=\boldsymbol{E}_{33} \\
8.96 \mathrm{GPa}\end{array}$ & $\begin{array}{l}\boldsymbol{G}_{12}=\boldsymbol{G}_{\boldsymbol{1 3}} \\
5.08 \mathrm{GPa}\end{array}$ & $\begin{array}{l}\boldsymbol{G}_{23} \\
2.99 \mathrm{GPa}\end{array}$ & $\begin{array}{l}v_{12}=v_{13} \\
0.32\end{array}$ & $\begin{array}{l}v_{23} \\
0.5 \\
\end{array}$ \\
\hline
\end{tabular}

The 3D FEM models of the migration experiment are shown in Fig. 3. They consist of an aluminum base in contact with a composite panel. The composite model has a total of 44 plies with the same layup and material properties as the tested specimens. Fine elements are used at the delamination front and near the loading points with a mesh size of $0.08 \mathrm{~mm}$. This element size meets the requirement of the cohesive zone size for correctly modeling delamination growth. Global element size of the composite panel is $0.3 \mathrm{~mm}$. The FE model of the DCB specimen has a total of 35217 brick elements (C3D8). Two zero-thickness cohesive interface layers are inserted at the bottom [0/90] interface and the top [90/0] interface (Fig. 3) and modeled with COH3D8 elements. The friction coefficient of $\mu=0.23$ is used for the contact between the aluminum base and the composite material ${ }^{5}$.

As composite materials show non-linear stress-strain response due to shear before ultimate failure, the matrix shear nonlinearity for IM7/8552 is assumed to follow the Ramber-Osgood form as described in Makeev et al. ${ }^{18}$ by fitting with the test data: 


$$
\gamma_{13}=\sigma_{13} / G_{13}+\left(\sigma_{13} / K\right)^{1 / \mathrm{n}}
$$

where $K$ is the secant intercept modukus and $n$ is the exponent of the fitting curve. The same shear stress-strain responses are used for the (1-2) and (2-3) planes. The values $K=248.9 \mathrm{MPa}$ and $n=0.248$ are used for the IM7/8552 material ${ }^{18}$.

The effect of geometry nonlinearity on the failure and delamination migration prediction is investigated first. Fig. 4 compares the numerical predictions between the FE models with and without nonlinear geometry modeling. The first property set of IM7/8552 material, as in Table $1^{8}$, is adopted. It can be observed that the model without considering the nonlinear geometry overpredicts the experimental utlimate load, and the resulted intial stiffness of the composite panel is also larger than the tested specimen stiffness. On the other hand, the FE model that takes into account the nonlinear geometry well predicts the experimental failure load of the especimen and is able to provide better stiffness prediction than the former model. It is therefore suggested that nonlinear geometry modeling should be activated for the migration problem.

In addition to the geometry nonlinearity, effects of the material shear nonlinearity on the DCB response are analyzed. Fig. 5 plots the stress-strain response predictions by the 3D CDM model with and without shear nonlinearity. All the models have nonlinear geometry activated. As can be seen, both the models predict similar failure loads and the initial stiffness of the specimen, revealing that shear nonlinearity has little impact on the response of the specimen prior to the peak load. Fig. 6 presents the starting migration points estimated by the two models. The FE model considering shear nonlinearity has delamination migration to be slightly delayed, since the matrix material is able to sustain higher strain before reaching its ultimate strain. The predicted migration point slightly increases from $13.07 \mathrm{~mm}$ for the original model without shear nonlinearity to $14.03 \mathrm{~mm}$ for the the one considering shear nonlinearity. Nevertheless, the effect of shear nonlinearity is minimal, meaning that mode I matrix failure mainly drives the delamination migration. This simulation finding agrees with the experiment observation by Ratcliffe et al. .

Given the discrepancy in the initil stiffess prediction as compared with the test data, an exploration study was performed using another set of collected elastic properties of IM7/8552 as listed in Table 2. ${ }^{17}$ Nonlinear geometry is included in the simulation model. Fig. 7 shows the comparison of the response predictions using two different sets of material properties. The initial stiffness predicted using property Set 2 (Table 2) shows that it agrees better with the test data. Both the models are capable of capturing the experimental failure load determined based on the onset growth of the delamination at the bottom (0/90) interface. The predicted matrix crack and delamination for the FEM using property Set 2 is given in Fig. 8. The predicted migration starting point using property Set 2 is $12.75 \mathrm{~mm}$ as compared to $13.07 \mathrm{~mm}$ using property Set 1 (Fig 6a). Generally, for a given set of composite material properties, the proposed 3D CDM model is capable of effectively predicting the transverse matrix crack and delamination migration through its interaction with the matrix cracks. 


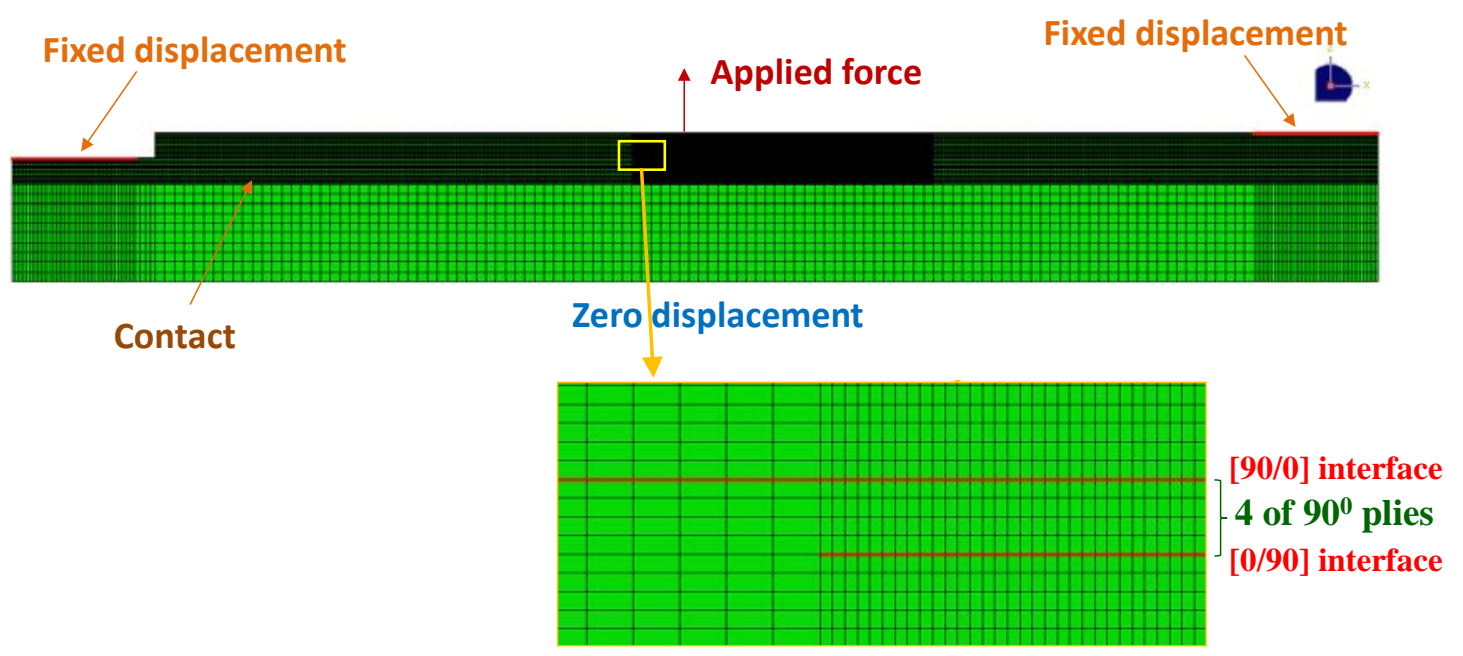

- Interfaces with zero-thickness COH3D8 elements

- Composite ply with C3D8 elements

Figure 3. 3D FEM model of the migration problem

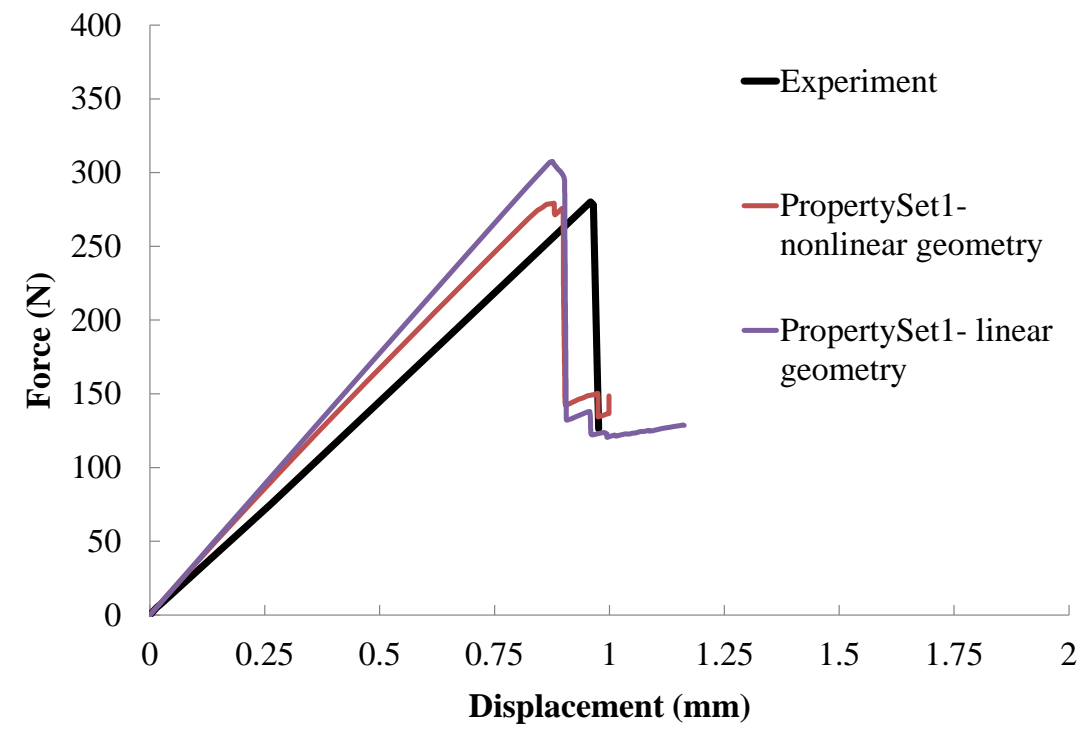

Figure 4. Comparison of response and failure predictions using the 3D CDM model with and without geometry nonlinearity with the test data ${ }^{8}$ 


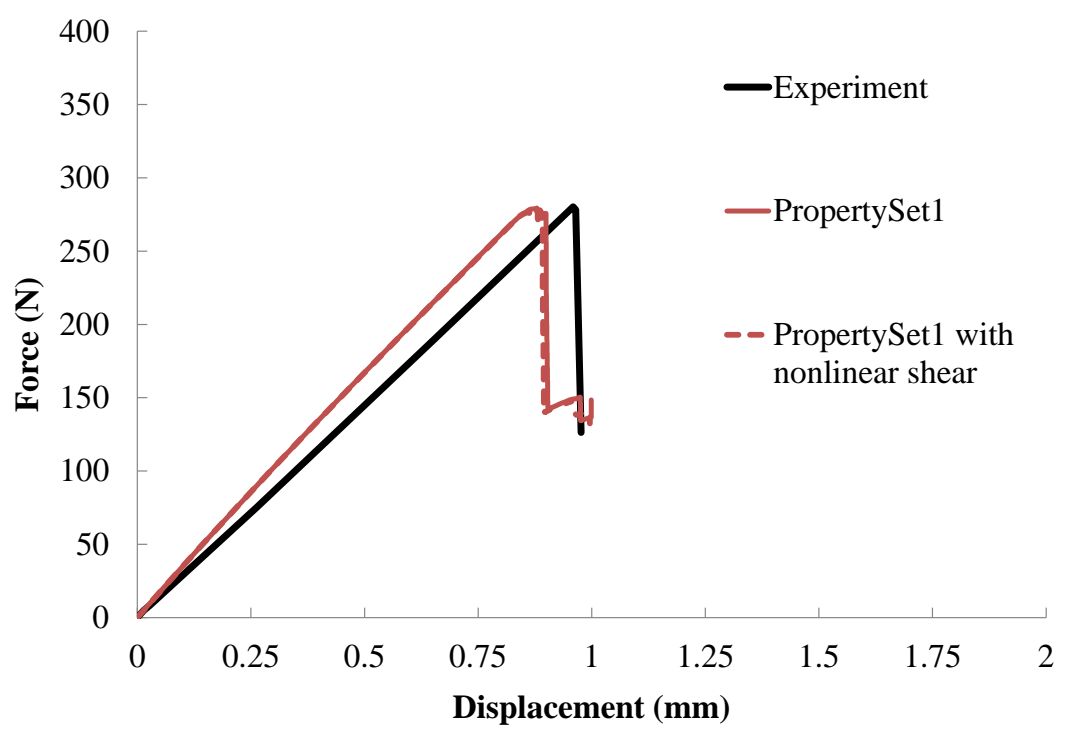

Figure 5. Comparison of response and failure prediction using the 3D CDM model with and without shear nonlinearity with the test data ${ }^{8}$

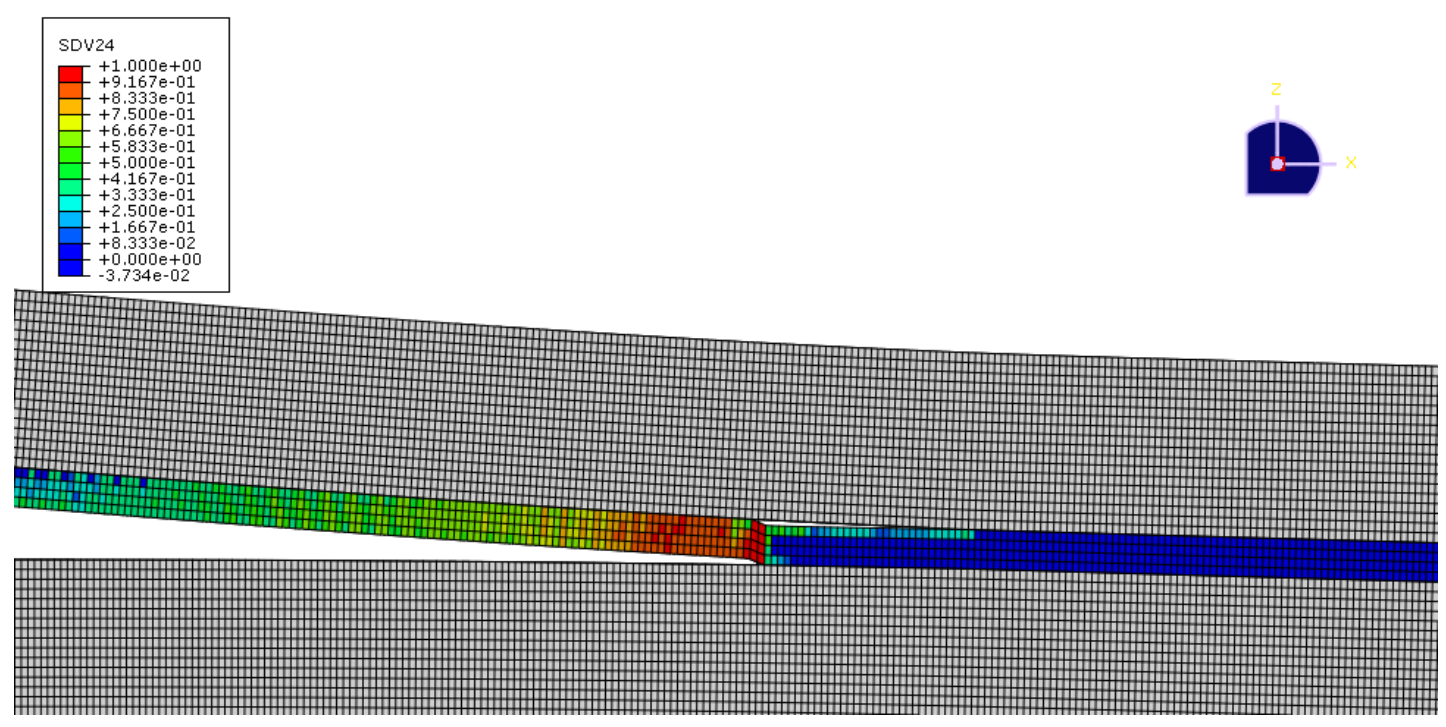

a. FE model with nonlinear geometry

Predicted migration distance: $13.07 \mathrm{~mm}$

Tested migration distance: $10-14 \mathrm{~mm}$ 


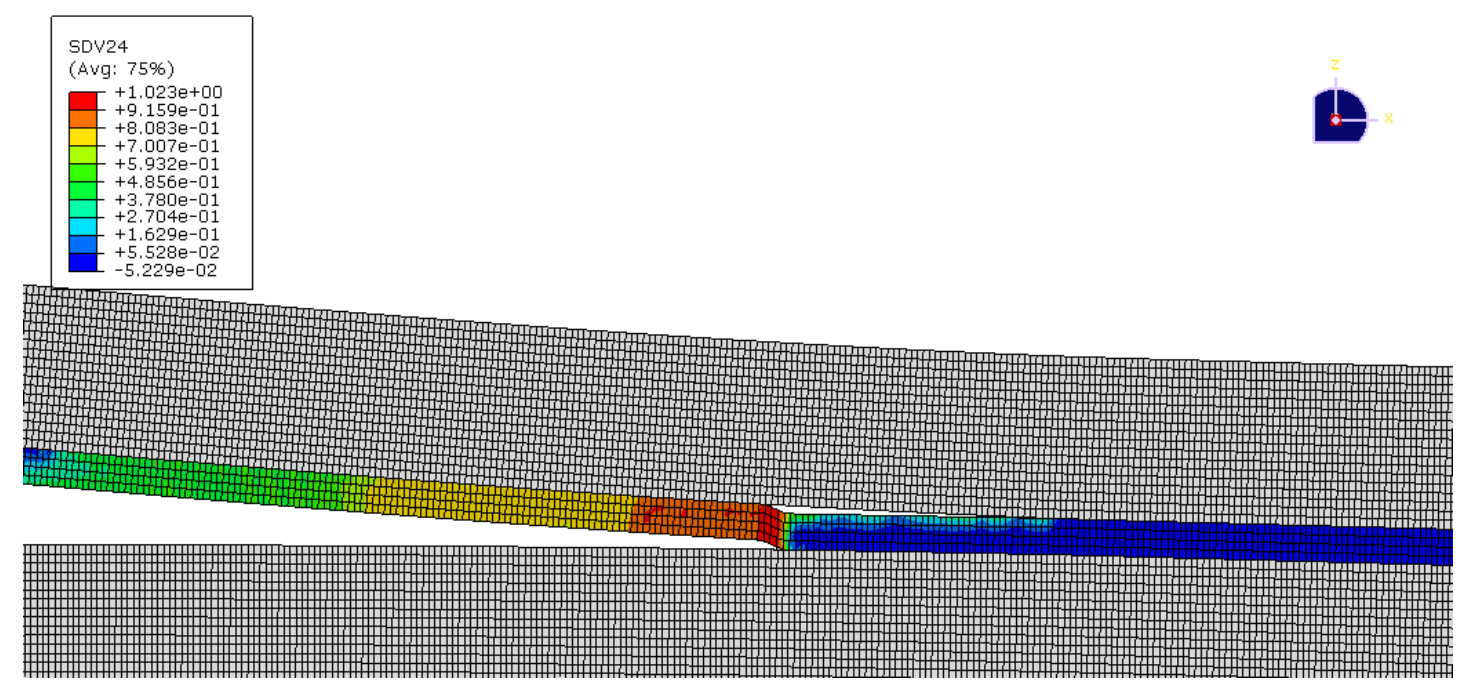

b. FE model with nonlinear geometry and shear nonlinearity Predicted migration distance: $14.03 \mathrm{~mm}$ Tested migration distance: $10-14 \mathrm{~mm}$

Figure 6. Matrix crack (in red) and delamination migration prediction using the 3D CDM model considering nonlinear geometry and shear

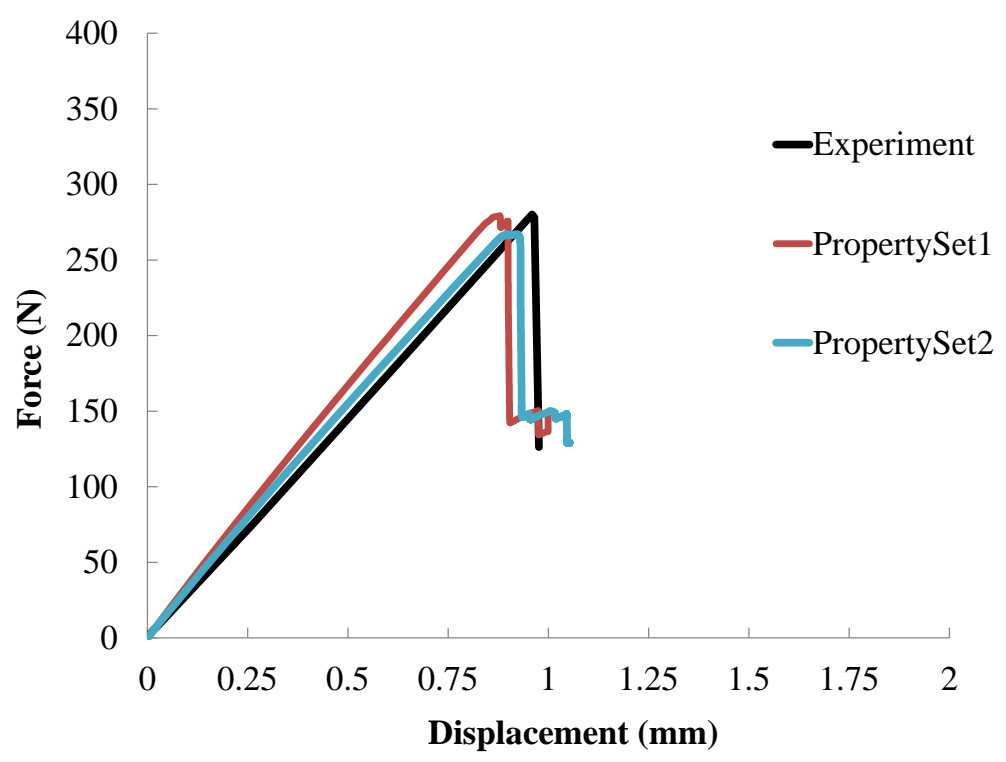

Figure 7. Effects of composite elastic modulus input on the initial stiffness prediction 

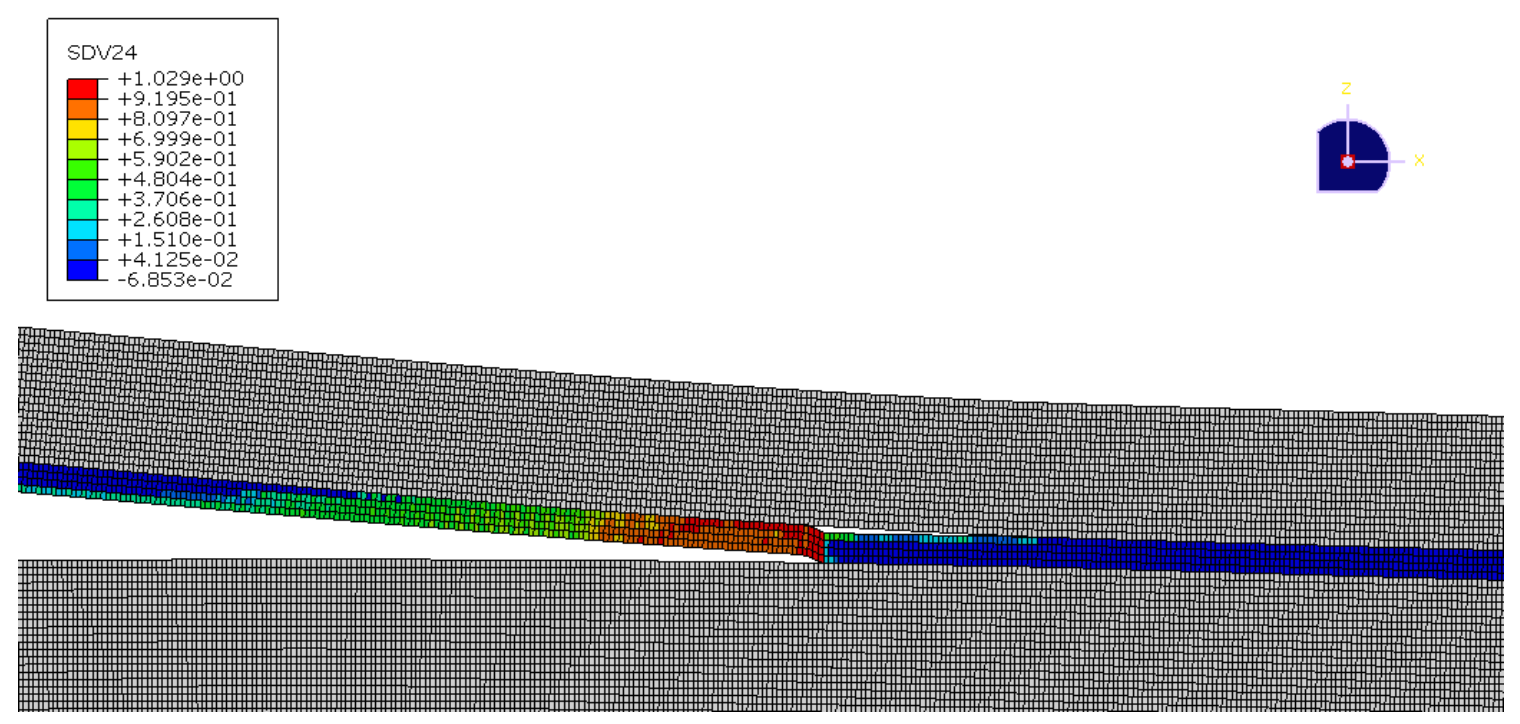

Predicted migration distance: $12.75 \mathrm{~mm}$

Tested migration distance: 10 - 14mm

\section{Figure 8. Illustration of matrix damage and delamination migration distance predicted using the 3D CDM} model with property Set 2

\section{Conclusions}

An enhanced CDM solution module has been developed to characterize the matrix crack orientation dependent stiffness degradation. Different from the conventional CDM approach, 3D Hashin failure criterion coupled with the crack band modeling approach has been implemented to determine the failure initiation followed by the energy driven failure progression. Given an arbitrary 3D stress state, an equivalent cohesive stress and crack opening displacement associated with the crack band model has been defined to compute the damage index in conjunction with the critical value of the strain energy release rates. A maximum principal stress has been employed to determine the orientation of a potential matrix crack and the local coordinate system for computing the discrete crack induced property degradation. The interaction of the delamination and matrix cracking has been captured using an Abaqus cohesive element at the ply interface and the enhanced CDM module implemented as the userdefined material for Abaqus.

The applicability and accuracy of the developed CDM based discrete crack modeling approach have been demonstrated through the simulation of the delamination migration tests conducted by Ratcliffe et al. ${ }^{8}$ for IM7/8552 cross-ply specimens. The effects of nonlinear geometry, nonlinear material and initial elastic properties have been studied by comparing model predictions with the test data. By considering nonlinear geometry, the predicted load-displacement responses of the DCB specimen agree well with the experimental results. However, the effect of shear nonlinearity in the material is found to be less influential for the delamination migration prediction. To understand the discrepancy in the initial stiffness prediction of the DCB specimen, an additional set of composite properties has been collected and used for the simulation. Better prediction in the initial stiffness has been achieved by using Set 2 data given in Table 2 .

While the full advantage of the CDM based discrete crack model has not been demonstrated using the coupon level DCB specimen, it is envisioned that the computational cost can be reduced significantly in the failure prediction of the composite laminates at sub-element and structural level with the presence of multiple delamination and matrix cracks with possible merging and intersection. 


\section{References}

1. Fang, E., Cui, X. and Lua, J., "A Phantom Paired Element Based Discrete Crack Network (DCN) Toolkit for Residual Strength Prediction of Laminated Composites”, 56 ${ }^{\text {th }}$ AIAA/ASCE/AHS/ASC Structures, Structural Dynamics, and Materials Conference, 2015.

2. Cui, X., Fang, E. and Lua, J., “A discrete crack network toolkit for Abaqus for damage and residual strength prediction of laminated composites”, Journal of Composite Materials, Vol. 51, No. 10, 2016, pp. 1355 - 1378.

3. Iarve, E.V., "Mesh independent modelling of cracks by using higher order shape functions", International Journal for Numerical Methods in Engineering, Vol. 56, 2003, pp. 869-882.

4. Iarve, E.V., Gurvich, M.R., Mollenhauer, D.H., Rose, C.A. and Dávila, C.G., "Mesh independent matrix cracking and delamination modeling in laminated composites”, International Journal for Numerical Methods in Engineering. Vol. 88, 2011, pp. 749-773.

5. Mollenhauer, D.Z, Iarve, E.V., Braginsky, M., Hoos, K., Breitzman, T. and Rapking, D., “Delamination Migration Modeling at the Micro/Meso-scales”, DURACOSYS, 2016.

6. Ling, D., Yang, Q. and Cox, B., 2009. “An augmented finite element method for modeling arbitrary discontinuities in composite materials”. International journal of fracture, Vol. 156, No. 1, pp.53-73.

7. De Carvalho N.V., Chen B.Y., Pinho S.T., Ratcliffe J.G., Baiz P.M., Tay T.E. "Modeling delamination migration in cross-ply tape laminates”. Composites Part A: Applied Science and Manufacturing”. Vol. 71, April 2015, pp. $192-203$.

8. Ratcliffe, J. G., Czabaj, M. W. and O’Brien T.K, “A Test for Characterizing Delamination in Carbon/Epoxy Tape Laminates”, NASA/TM-2013-218028, 2013.

9. Pernice M. F., De Carvalho N.V. and Hallett S. R. "Experimental study on delamination migration in composite laminates”. Composites Part A: Applied Science and Manufacturing, Vol 73, Jun 2015, pp 20-34.

10. Hashin Z, "Failure criteria for unidirectional fibre composites", ASME Journal of Applied Mechanics, Vol. 47, No. 2, 1980, pp. 329-334.

11. Rots, G., Nauta, P., Kusters, G.M.A., Blaauwendraad, J., "Smeared crack approach and fracture localization in concrete”, HERON, Vol. 30, No. 1, 1985, pp. 1-48.

12. Zhang, D., Waas, A. M., and Yen, C. F., "Progressive damage and failure response of hybrid 3D textile composites subjected to flexural loading, Part II: Mechanics based multiscale computational modeling of progressive damage and failure,” International Journal of Solids and Structures, Vol. 75-76, 2015, pp. 321-335.

13. Zhang, D., Patel, D., and Waas, A. M., "A novel two-scale progressive failure analysis method for laminated fiberreinforced composites,” 56th AIAA/ASCE/AHS/ASC Structures, Structural Dynamics and Materials Conference, AIAA SciTech, Kissimee, Florida, January 5-9, 2015, AIAA 2015-0969.

14. Pham D.C., Sun X.S., Tan V.B.C., Chen B., Tay T.E., "Progressive Failure Analysis of Scaled Double-Notched Carbon/Epoxy Composite Laminates”, International Journal of Damage Mechanics, Vol. 21, No. 8, 2012, pp. $1154-1185$.

15. Pham D.C., Sun X.S., "Experimental and computational studies on progressive failure analysis of notched cross-ply CFRP composite”, International Journal of Computational Materials Science and Engineering, Vol. 1, No 3, 2012.

16. Krueger R, "Development of and application of benchmark examples for mixed mode I/II quasi-static delamination propagation predictions”, NASA-CR-2012-217562, National Aeronautics and Space Administration; 2012.

17. Makeev, A., et al. “Analysis Methods Improving Confidence in Material Qualification for Laminated Composites”, AHS 72nd Annual Forum, West Palm Beach, Florida, USA; 2016.

18. Makeev, A., G. Seon, and E. Lee, "Failure Predictions for Carbon/Epoxy Tape Laminates with Wavy Plies”. Journal of Composite Materials. Vol. 44, No. 3, 2009, pp. 95-112. 